\title{
Innovative Approaches to Increase Service Life of Poplar Lightweight Hardwood Construction Products
}

\author{
Joris C.R. Van Acker, Xiuping Jiang and Jan B.B. Van den Bulcke \\ Ghent University (UGent), Laboratory of Wood Technology (UGent-Woodlab), Coupure links 653, \\ 9000 Ghent, Belgium, joris.vanacker@ugent.be
}

\begin{abstract}
During the second half of last century the forestry-wood chain has evolved and today ecosystem services in a sustainability framework are important. Forests are intended to provide services for the bio-economy, human health, biodiversity and climate control. An increased need for more renewable resources both for material and energy use has initiated extra interest for the potential to produce more lignocellulosic biomass, in short to increase wood production. One option is to provide in complementary production in planted forests. Both forestry and agriculture can take part in this. The cultivation of poplar hybrids in the temperate regions is a key option for the current and future bioeconomy. These fast-growing trees are producing lightweight hardwood with a low natural durability, but with an important potential as construction material especially as engineered wood products. All wood protection methods are of interest to be evaluated for this wood resource, making it suitable even for high quality applications. Poplar, for many reasons, has been nominated as hardwood with the best potential to perform similarly as softwoods for applications in wood construction. Benchmarking with wood species like spruce is relevant for several engineered wood products like plywood, LVL and even CLT. Wood treatments to increase durability have evolved from traditional wood preservation towards modification techniques such as thermally modified timber. Innovative poplar based products have been assessed on their performance and are designed to fit for purpose in relation to a specific combination of use class and service life. Introducing innovative poplar based construction product for green building requires adequate testing tools. Performance based assessment should allow to integrate different protective measures. Related to moisture dynamics and the linked fungal decay risk, opportunities to extend service life are manifold. Treatment can be differentiated e.g. for cladding (building envelope) and loadbearing construction components. Simple or sophisticated modification processes can alter the equilibrium moisture content. The use of wood based panels and new engineered wood products allow for better moisture control impacting fungal decay risk, but also alter the probability of insect damage. This paper intends to present several innovative poplar based construction products and show some cases of benchmarking in relation to an integrated service life approach.
\end{abstract}

Keywords: Poplar, Engineered Wood Products, Wood Protection, Wood Modification.

\section{Introduction}

In recent decades, the interest for building taller all-timber structures using engineered timber materials such as cross-laminated timber (CLT) has increased substantially, especially in the framework of sustainable use of resources and the positive carbon footprint of wood materials. The specific structure of CLT panels improves the dimensional stability, bending strength and other mechanical properties, thus enabling its use as load-bearing elements in various constructions. Especially in Europe, mainly spruce (Picea abies) is used for this purpose, while other wood species have been largely overlooked. Poplar, for example, is considered a potential species to be used in CLT as a substitute of spruce. Poplar is of interest as fast-growing tree 
species providing lightweight material. It is a majorly important tree species in planted forests and agroforestry worldwide.

However, since poplar in general has a very low natural durability, we need to acquire sufficient knowledge on its behavior when incorporated in CLT. Therefore there is a need to focus on moisture dynamics (Van Acker 2017), which are in direct relation to the fungal susceptibility and thus decay resistance and service life of the product. Hence investigations should deal with moisture sorption properties (including e.g., equilibrium moisture content, fiber saturation point and thermodynamic analysis) of unmodified and modified poplar products, and test the fungal susceptibility as well, aiming at incorporation in CLT products.

\section{Durability Challenges for CLT (Cross Laminated Timber)}

Wood, as a renewable and environmentally friendly material, has been widely exploited and used in the construction industry. However, sawn wood, timber and lumber have limited dimensions related to the tree's dimensions. This can be overcome by producing engineered wood products and especially mass timber. In recent decades, the interest for building taller alltimber structures using such EWPs has increased substantially. Engineered wood, also called composite wood, man-made wood or manufactured board, includes a range of derivative wood products which are manufactured by binding or fixing the strands, particles, fibers, or veneers or boards of wood, together with adhesives, or other methods of fixation to form composite materials. Mass timber construction uses large prefabricated engineered wood members for

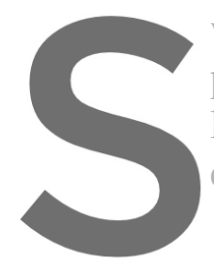
wall, floor and roof don projects. These product laminated timber (NLT element (bar/trusses),
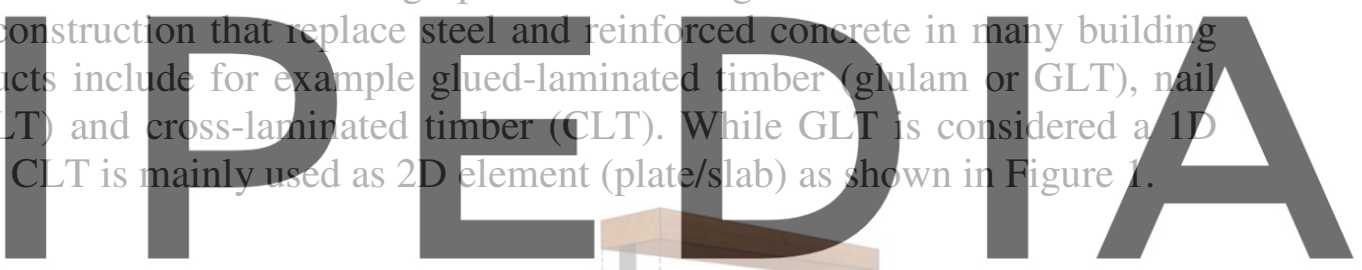

Register for free at https//www.scipedia.com to download the version without the watermark
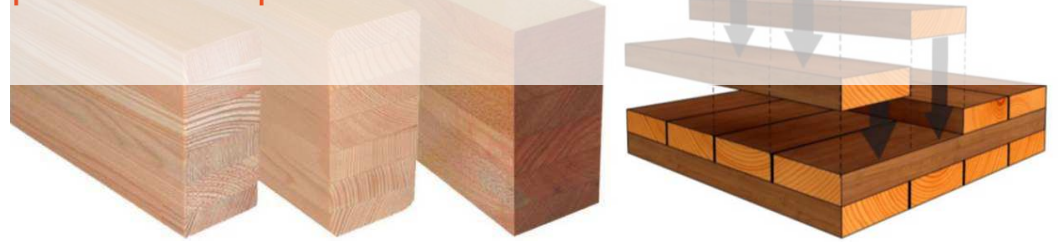

Figure 1. GLT ('1D' elements at the left hand side) vs CLT('2D' element at the right hand side). (Canada Wood, 2018)

GLT exists since long and more recently also CLT has become popular. The production of CLT is about 0.8 million $\mathrm{m}^{3}$ worldwide, with $90 \%$ of the CLT production in Europe. An increase of $10 \%$ on an annual basis of CLT as a building product shows potential for not only softwood species, but also hardwood species. Within the next decade, therefore, CLT could become as important as glue-laminated timber, and it is likely to extend the limits of tall wooden buildings upwards. At present, most central European producers are using spruce (Picea abies) as main wood species in CLT. New studies began to focus on hybrid CLT, where the hybrid build-up can be designed as a rigid composite with small error on exact analysis. The novel investigations reveal the potential to overcome low rolling shear properties in cross layers of mixed softwood-hardwood (e.g. beech and spruce) CLT build-ups for structural elements in 
the building sector (Aicher et al. 2016). These approaches show potential to use also other species than spruce. New technologies such as CLT (cross laminated timber) have accelerated the construction of multi-story wooden buildings and weather protection during construction has not always been used but moisture safety remains important (Mjörnell and Olsson, 2019).

Although CLT is clearly an engineered wood products with great potential and by many considered adequate for high rise buildings in relation to mechanical and structural properties as well fire safety (Brandner et al. 2016, Barber 2018) the topic of sensitivity to wood rotting fungi might be underestimated. Several authors have already indicated that increased moisture in the framework of building physics, both condensation and leakage cannot be fully avoided and some preventive protection or monitoring might be required. Treatment options for mass timber products, particularly cross laminated timber (CLT) remain however to be addressed (Mankowski et al. 2018). Since wood species currently used to fabricate CLT are non-durable, and current design standards do not properly address incorporation of preservative treatments into these systems some experiments using a ground proximity test were proposed. Using mass timber such as CLT, but also GLT (glulam) and related engineered wood products require special attention when used in exterior applications (Morris 2015). Already some recommendations on feasible treatments of CLT have been compiled to increase awareness of decay risk and possible preventive measures (Wang et al. 2018). For tropical regions this could even be extra underpinned (Oliveira et al. 2018).

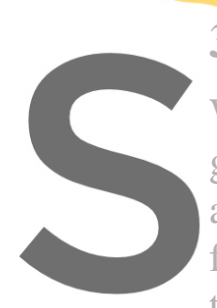

\section{Assessing the Potential of Poplar}

With the increasing demand of wood materials, plantations or planted forest consisting of fast-
growing tree species increasingly contribute in providing a complementary wood resource and
as such lower the pressure on natural forests. The cultivation of hybrid poplar is an eminent
fast-growing species. As a fast-growing tree species in China ( 8.5 mithion ha) and Europe (c) ose
to 1 million ha), the major poplar hybrid plantations are now mainly focusing on plywood production. For traditional products like plywood, but also constructional timber, poplar or

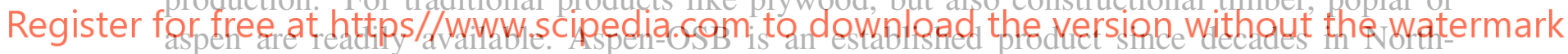

America. Specific strength and stiffness are interesting characteristics, but the ability to select quality trees with a major impact on production yieid are an asset as well. Today researchers are reassessing the potential of solid timber products using poplar wood. Dimensional stability and biological durability are improved using modern wood modification methods besides traditional treatments. In this respect both glulam and CLT (cross laminated timber) show major potential eventually in combination with e.g. thermal modification.

In literature, it has been assessed that poplar and poplar products like plywood are considered non-durable (De Boever et al. 2008), thus protection can be necessary to comply with service life expectations in harsh environments (Zannutini et al. 2003; De Smet and Van Acker 2006; Van Acker 2008). When considering moisture dynamics some plywood products can perform quite well in outdoor conditions without ground contact (Van den Bulcke et al. 2011, Li et al. 2016). The potential of poplar is worth exploring. In some studies, poplar has been assessed as alternative for softwood to produce glulam, and combinations with other hardwoods are investigated. One study revealed that the beams composed using a specific eucalyptus clone, by its own or in combination with poplar, showed outstanding mechanical performance and the best structural efficiency. Additionally, the bonding quality, at the interface between the two 
species, proved to be excellent (Castro and Paganini 2003). Clearly, poplar is a promising wood species to obtain enhanced quality in very good products based on both thermal and chemical wood modification, as well as by several other treating processes used adequately (Fraanje 1998). As such wood protection and modification can increase the potential use of poplar and poplar products considerably. Some Garnica plywood products developed recently are good examples (Sufrategui et al. 2016) and prove that they can be used to produce building products in a fit-for-purpose concept.

\section{Innovation and Treatments to Enhance Service Life}

Plywood has been the model material to investigate the impact of moisture dynamics on service life prediction. Plywood outperforms in practical circumstances what can be expected from fungal testing (Van den Bulcke et al. 2011, De Windt et al. 2018). Although in many cases low durability wood species are used and the impact on fungal growth of the glue is only temporarily, many plywood products last quite long in outdoor out of ground contact applications. The fact that such wood products under use class 3 (EN 335) circumstances can exhibit limited moisture uptake in combination with ease to dry, is not yet fully considered as an extra resistance to decay. These moisture dynamics can be assessed as time of wetness (ToW) and simulated using exterior continuous moisture measurements (CMM) as well as soaking - drying lab methods as defined in the standard CEN/TS 16818 (Van Acker et al. 2017b). The service life approach combining performance in relation to end use based on

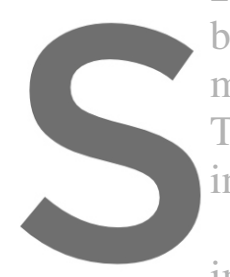
biocidal components, structural properies and
more info than the simple material resistance o
This will provide a tool towards better jntegrat
industry chain (Van Acker 2019).
Although poplar CLT based on a range of important parameters biocidal treatments, and on low impact thermal and chemical modification that improves

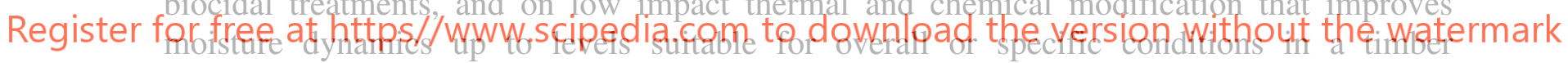

construction based on poplar CLT. Such treatments need to be explicitly selected based on minimal requirements and can relate to less than perfect wood protection but fit for purpose (Van Acker et al. 2017a). Recently Singh et al. (2019) showed that untreated OSB and CLT based on radiate pine were very susceptible to decay, while LVL was less susceptible. Simple boron surface treatments are suggested as potential option to lower the risk for decay. Furthermore this research indicated that moisture sorption behavior is important for experimental work especially when products treated by selected protection or modification methods. Such experiments under different experimental conditions (by changing the temperature and relative humidity) allow to provide equilibrium moisture content (EMC) modeling based on statistical analysis linked to identified significant effects from the modification. Empirical models can be compared and selected to fit the data (Jiang 2019) providing moisture sorption isotherms (MSI). Based on these data hysteresis will be analyzed and a thermodynamic analysis will be carried out.

To face the durability performance, fit for purpose and environmental challenges, the concept of introducing innovative engineered wood products is to focus on lightweight poplar, being at one hand strategically important in European forestry, while at the other hand the 
technology can be transferred to other lightweight hardwoods, as well as softwoods. To achieve the performance requirements with increased cost-effectiveness, an integrated approach is applied combining wood modification (wood engineering), protection (preservation and coating) and fire resistance, the latter governing for many high-end building applications such as multi-story buildings. This leads into a specific new generation of products which are emerging: engineered and multi-level treated wood in the form of LVL, CLT, LSL and I-beam or I-joists made thereof.

Wood modification technologies like acetylation, furfurylation and different thermal modifications are intended anyhow to alter chemical and physical properties. When carried out to a sufficient level throughout the wood, these processes protect it from rot by making it "inedible" to most micro-organisms and fungi, without requiring biocides. It greatly reduces the wood's tendency to swell and shrink, making it less prone to cracking and ensuring that, when painted, it requires dramatically reduced maintenance. The innovation potential of engineered wood products from modified poplar wood is huge. TMT (thermally modified timber) poplar is already considered a SoA product. However it is always critical on lower mechanical strength, and therefore a load bearing application can be hard to achieve. Specific research on THM (thermo-hydro-mechanical) densification treatments on trembling aspen and hybrid poplar can alter some mechanical properties in a positive sense (Fang et al. 2019) and is considered an opportunity for future environmentally friendly wood products (Sandberg et al. 2013). This type of treatments are often considered of interest for low density hardwoods (Bao et al. 2017). Some treatments even de not focus on fungal decay resistance but are intended to improve delamination resistance (Han et al. 2017).
Contrary to thernal modification, chemical modification of poplar is not yet fully
some technicalities due to difficult to impregnate transition zones. Chemical impreguation
processes, e.g. with self-polyrnerizing and crosslinking agent can furthermore imply that the
mechanical strength will be preserved. (or even increased) and thus giving the innovative

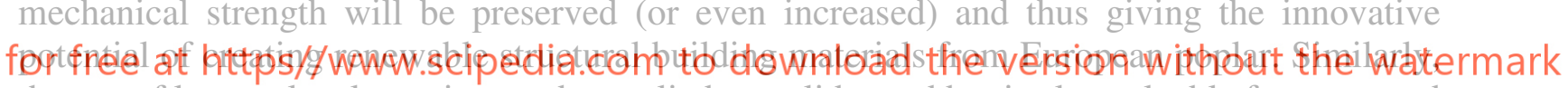
the use of low molecular resins can be applied on solid wood but is also valuable for e.g. stand based products like OSB (Wan and Kim 2004). Chemical modifications and in particular the curing step when resin treatments are applied, can lead to some embrittlement (Xie et al. 2013).

Building with poplar can be considered a forgotten reality that is picked up recently in an attempt to use lightweight hardwoods in construction (Kesteloot and Hudel 2016). Poplar CLT has been explored alongside GLT by several researchers (Kramer et al. 2014, Wang et al. 2014) and several companies in Europe have recently started producing this product at pilot scale. For poplar we can integrate all these trends by combining a fast growing wood resource from specific poplar cultivation, introducing this for construction and applying fit-for-purpose treatments to enhance material resistance. An example being explored in this context is poplar CLT, optionally thermally treated when decay could be a risk. Thermal treatment of poplar wood has been identified as having good potential (De Boever et al. 2016), being however only one of the options to increase service life under different use classes.

In Table 1 an overview is provided on how the service life of different engineered wood products could be increased. The different engineered wood products are subdivided in categories depending on the components constituting the product: strands, veneer and timber. For each category a wood based panel product as well as a beam like product is used as example. 
The use of durable wood species is clearly related to the use of primarily heartwood which is often difficult to achieve in full. Vacuum pressure based wood preservation of the final product is often limited by the treatability. Glue-line additives are mainly useful when thin veneers or strands need to be protected. A third option related to wood preservation technology is spraying a diffusible component based product (e.g. borates) on the surface. Modification technologies might have some impact on mechanical properties and hence not fully adequate for loadbearing applications, but thermal modification for full panel products and chemical modification of strands prior to incorporation in a panel is potential technology. Finally resin treatments have similar or even better potential than glue-line additives and could also be applied as modification methods for timber based products. Applying coatings to control moisture dynamics is mainly useful for veneer and timber based products.

Table 1. Options to increase service life of Engineered Wood Products (EWP).

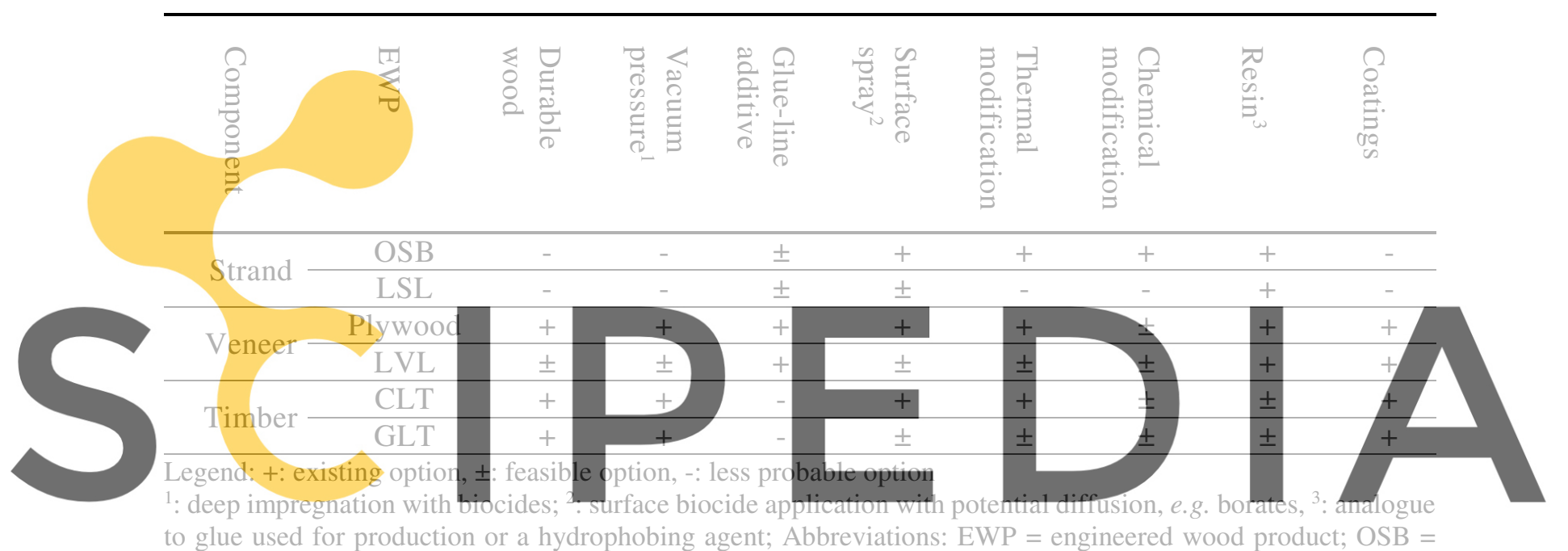

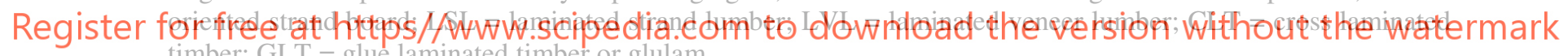
timber; GLT = glue laminated timber or glulam.

\section{Conclusions and Future Perspectives}

The overall concept of introducing innovative engineered wood products based on fast growing plantation trees like hybrid poplars to achieve results, relate to the following objectives: (1) to link methodology (service life prediction) and product development (poplar EWP's - glulam \& CLT; plywood \& LVL; OSB and LSL); (2) to focus on European hardwood species; and (3) to integrate options for untreated and protected products through both biocidal and non-biocidal treatment. A holistic approach is needed to combine resistance to fungal decay, insect attack, fire, dimensional stability; in due consideration of different applications: construction (both loadbearing and not) from damp up to marine environments, interior and exterior applications (cladding, garden furniture,...), transport (caravans, containers, automotive,...) and their requirements in terms of time of wetness, aesthetics, weathering, maintenance, long-term mechanical properties (creep, mechano-sorptive behaviour, impact of treatment), as well as in terms of life cycle assessment and life cycle costing performance. All wood protection and modification methods are of interest to be evaluated for this plantation wood resource, making it suitable even for high quality applications. Poplar, for many reasons, has been nominated as 
hardwood with the best potential to perform similarly as softwoods for applications in wood construction. Benchmarking with wood species like spruce is relevant for several engineered wood products like plywood, LVL and even CLT. Wood treatments to increase durability have evolved from traditional wood preservation towards modification techniques such as thermally modified timber depending on the performance required or fit-for-purpose in relation to a specific combination of use class and service life.

\section{Acknowledgements}

The authors gratefully acknowledge the support by the Flemish Research Institute for Nature and Forest (INBO) in relation to research on hybrid poplars as well as the CSC grant 201906320060 provided for Xiuping Jiang.

\section{ORCID}

Joris Van Acker: https://orcid.org/0000-0002-8961-0176

Xiuping Jiang: https://orcid.org/0000-0002-0752-2691

Jan Van den Bulcke: http://orcid.org/0000-0003-2939-5408

References

Aicher S., Hirsch M. and Christian Z. (2016). Hybrid beech and spruce cross-laminated timber. Proceedings of WCTE World conference on timber engineering, Vienna, Austria, 7p.

Bao, M., Huang, X., Jiang, M., Yu, W. and Yu, Y. (2017). Effect of thermo-hydro-mechanical densification on microstructure and properties of poplar wood (Populus tomentosa). J Wood Sci 63:591-605

Barber, D. (2018) Fire safety of mass timber buildings with CLT in USA. Wood and Fiber Science 50:83-95.

Brandner, R., Flatscher, d., Ringho fer, A., Schickhofer, G. and Thiel, A. (2016) Cross laminated overyiew and development. European Journal of Wod and Wood Products 74(3):331-351.

Canada Wood (2018).

http://www.sohu.com// $/ 2$

Castro G. and Paganini F. als Roh- und Werkstoif 6

De Boever, L., Van Acker, J., Vansteenkiste, D. and Stevens, M. (2008). Preservative treatment of willow wood (Salix alba): product retention and spatial distribution. Wood Research 53: 29-42.

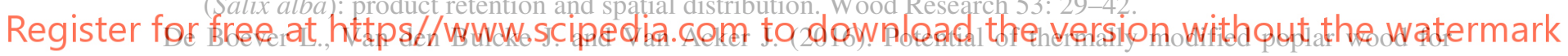
construction products. Proceedings of the 2nd Conference on Engineered Wood Products based on Poplar/Willow Wood, León, Spain: 107-112.

De Smet, J. and Van Acker, J. (2006). Testing methodology and CE-marking for biological performance of plywood for exterior construction purposes. Proceedings of the COST Action E44/E49 conference on Wood resources and panel properties, Valencia, Spain.

Defoirdt, N., Sen, A., Dhaene, J., De Mil, T., Pereira, H., Van Acker, J. and Van den Bulcke, J. (2017). A generic platform for hyperspectral mapping of wood. Wood science and technology, 51(4), pp.887-907.

De Windt, I., Li, W., Van den Bulcke, J. and Van Acker, J. (2018). Classification of uncoated plywood based on moisture dynamics. Construction and Building Materials.158:814-822.

Fang, C-H., Cloutier, A., Jiang, Z-H., He, J-Z. and Fei B-H. (2019). Improvement of Wood Densification Process via Enhancing Steam Diffusion, Distribution, and Evaporation. BioResources 14(2):3278-3288

Fraanje, P.J. (1998). Poplar wood for purlins; an evaluation of options and environmental aspects. Holz als Rohund Werkstoff 56:163-169.

Han, Y., Park, Y., Chang, Y-S., Chung, H., Eom, C-D. and Yeo, H. (2017). Improvement of shear strength, wood failure percentage and wet delamination of cross-laminated timber (CLT) panels made with superheated steam treated (SHST) layers of larch wood. Holzforschung 71(11).

Jiang, X., Li H., Ramaswamy, H. S., Zhu S. and Yu Y. (2019). Moisture sorption isotherms and isosteric heats of sorption of high-pressure treated paulownia wood under different storage conditions. Transactions of the ASABE. 62(1), 105-114. DOI: 10.13031/trans.12899 
Kesteloot, S. and Hudel, M. (2016). Study of the stress-grading of poplar for a structural use. Proceedings of the 2nd Conference on Engineered Wood Products based on Poplar/Willow Wood, León, Spain: 51-56.

Kramer, A., Barbosa, A., and Sinha, A. (2014). Viability of Hybrid Poplar in ANSI Approved Cross-Laminated Timber Applications. Journal of Materials in Civil Engineering, 26(7)

Li, W., Van den Bulcke, J., De Windt, I., Dhaene, J. and Van Acker, J. (2016). Moisture behavior and structural changes of plywood during outdoor exposure. European Journal of Wood and Wood Products 74(2):211-221.

Mankowski, M.E., Shelton, T.G., Kirker, G. and Morrell, J.J. (2018). Field Evaluation of Douglas-fir Cross Laminated Timber in A Ground Proximity Protected Test in Mississippi, Porceedings of the American Wood Protection Association Volume 114: 132-137.

Mjörnell, K. and Olsson, L. (2019). Moisture Safety of Wooden Buildings - Design, Construction and Operation. Journal of Sustainable Architecture and Civil Engineering. 1:29-35.

Morris, P. (2015) Optimizing the Design of Mass Timber in Exterior Applications. FP Innovations, cwc.ca. 23p.

Oliveira, G.L., de Oliveira, F.L. and Brazolin, S. (2018). Wood preservation for preventing biodeterioration of Cross Laminated Timber (CLT) panels assembled in tropical locations. Procedia Structural Integrity 11:242249.

Sandberg, D., Haller, P. and Navi, P. (2013). Thermo-hydro and thermohydro-mechanical wood processing: An opportunity for future environmentally friendly wood products. Wood Material Science \& Engineering, 8(1): 64-88.

Singh, T., Page, D. and Simpson, I. (2019). Manufactured structural timber building materials and their durability. Construction and Building Materials. 217:84-92.

Sufrategui, M.A., Albiñana, J., Alvarez, J. and Crespo, O. (2016). The Garnica brick: a structural insulated sandwich panel based on modified poplar plywood and an XPS core. In Van Acker J. (eds) Proceedings of the 2nd Conference on Engineered Wood Products based on Poplar/willow Wood. León, Spain.

Van Acker, J. (2008). Development of decay in preservative treated poplar plywood. In J. Van Acker and Y. Hua (eds) Proceedings of the Conference on Engineered Wood Products Based on Poplar/Willow Wood. Nanjing, PRChina, ISBN 9789 d8

Van Acker, J. (2017) Moisture dyna 26.

Van Acker, J., De Windt, selection of wood mater Building Materials and Components. p7.

Van Acker, J., Van den Bulcke, J., De Windt, I. and De Boever, L. (2017b). Continuous moisture measurements

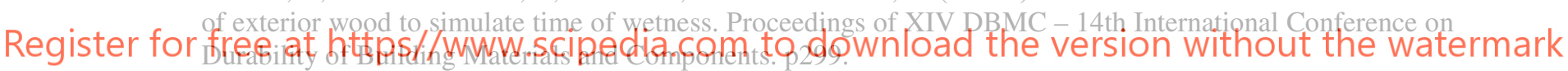

Van Acker, J. (2019). Towards better integration of wood protection in the forestry wood industry chain, case study on hybrid poplar. Proceedings of the International Research Group on Wood Protection Doc. № $19-$ $50359,19 \mathrm{p}$.

Van den Bulcke, J., Boone, M., Van Acker, J. and Van Hoorebeke, L., (2009). Three-dimensional X-ray imaging and analysis of fungi on and in wood. Microscopy and Microanalysis, 15(5), pp.395-402.

Van den Bulcke, J., De Windt, I., Defoirdt, N., De Smet, J. and Van Acker, J. (2011). Moisture dynamics and fungal susceptibility of plywood. International Biodeterioration \& Biodegradation 65(5):708-716

Wan, H. and Kim, M.G. (2006). Impregnation of southern pine wood and strands with low molecular weight phenol-formaldehyde resins for stabilization of Oriented Strandboard. Wood and Fiber Science. 38(2):314-324

Wang, J.Y., Stirling, R., Morris, O.I., Taylor, A., Lloyd, J., Kirker, G., Lebow, S., Mankowski, M.E., Barnes, H.M. and Morrell, J.J. (2018). Durability of mass timber structures: a review of the biological risks. Wood and Fiber Science, 50:110-127.

Wang, Z., Fu, H., Chui Y-H. and Gong, M. (2014). Feasibility of using poplar as cross layer to fabricate crosslaminated timber. Proceedings of the World Conference on Timber Engineering (WCTE), 5p.

Xie, Y., Fu, Q., Wang, Q., Xiao, Z. and Militz, H. (2013). Effects of chemical modification on the mechanical properties of wood. Eur. J. Wood Prod. 71:401-416

Zanuttini, R., Nicolotti, G. and Cremonini, C. (2003). Poplar plywood resistance to wood decay agents: efficacy of some protective treatments in the light of the standard ENV 12038. Annals of Forest Science 60:1-7 